ARTICLE

\title{
Solid-state synthesis of ordered mesoporous carbon catalysts via a mechanochemical assembly through coordination cross-linking
}

Pengfei Zhang1, Li Wang ${ }^{1,2}$, Shize Yang ${ }^{3}$, Jennifer A. Schott ${ }^{1,4}$, Xiaofei Liu², Shannon M. Mahurin', Caili Huang ${ }^{5}$, Yu Zhang ${ }^{6}$, Pasquale F. Fulvio ${ }^{7}$, Matthew F. Chisholm ${ }^{3}$ \& Sheng Dai ${ }^{1,4}$

Ordered mesoporous carbons (OMCs) have demonstrated great potential in catalysis, and as supercapacitors and adsorbents. Since the introduction of the organic-organic self-assembly approach in 2004/2005 until now, the direct synthesis of OMCs is still limited to the wet processing of phenol-formaldehyde polycondensation, which involves soluble toxic precursors, and acid or alkali catalysts, and requires multiple synthesis steps, thus restricting the widespread application of OMCs. Herein, we report a simple, general, scalable and sustainable solid-state synthesis of OMCs and nickel OMCs with uniform and tunable mesopores $\left(\sim 4-10 \mathrm{~nm}\right.$ ), large pore volumes (up to $0.96 \mathrm{~cm}^{3} \mathrm{~g}^{-1}$ ) and high-surface areas exceeding $1,000 \mathrm{~m}^{2} \mathrm{~g}^{-1}$, based on a mechanochemical assembly between polyphenol-metal complexes and triblock co-polymers. Nickel nanoparticles $(\sim 5.40 \mathrm{~nm})$ confined in the cylindrical nanochannels show great thermal stability at $600^{\circ} \mathrm{C}$. Moreover, the nickel OMCs offer exceptional activity in the hydrogenation of bulky molecules $(\sim 2 \mathrm{~nm})$.

\footnotetext{
${ }^{1}$ Chemical Sciences Division, Oak Ridge National Laboratory, Oak Ridge, Tennessee 37831, USA. ${ }^{2}$ Key Laboratory for Advanced Materials and Research Institute of Industrial Catalysis, East China University of Science and Technology, Shanghai 200237, China. ${ }^{3}$ Materials Science and Technology Division, Oak Ridge National Laboratory, Oak Ridge, Tennessee 37831, USA. ${ }^{4}$ Department of Chemistry, University of Tennessee, Knoxville, Tennessee 37996, USA.

${ }^{5}$ Neutron Science Directorate, Oak Ridge National Laboratory, Oak Ridge, Tennessee 37831, USA. ${ }^{6}$ Department of Chemical and Biomolecular Engineering, Vanderbilt University, Nashville, Tennessee 37235, USA. ${ }^{7}$ Department of Chemistry, University of Puerto Rico, Rio Piedras Campus, San Juan, Puerto Rico 00931, USA. Correspondence and requests for materials should be addressed to L.W. (email: wangli@ecust.edu.cn) or to S.D. (email: dais@ornl.gov).
} 
B ecause of the uniform pore channel, large mesopore size, high pore volume and good chemical inertness, ordered mesoporous carbons (OMCs) have already demonstrated promising performance in a number of applications such as catalysis, separation, fuel cells and supercapacitors ${ }^{1-5}$. The wide and ordered pore channels are especially useful for the separation of large biomolecules or natural products and, at the same time, provide broad space for fast mass transfer, which is highly beneficial in high-rate supercapacitors and heterogeneous catalysis $^{6-8}$. In general, two methods-a hard-templating route and a soft-templating strategy-have been used for the fabrication of OMCs. The hard templating technology usually starts with the synthesis of an ordered mesoporous silica, followed by inverse replication of the template using organic polymerization ${ }^{9-11}$. Since 1999-when the Ryoo group and the Hyeon group introduced OMCs for the first time-numerous OMCs with precisely controlled mesostructures have been synthesized ${ }^{12,13}$. However, the sacrificial nature of the ordered silica template together with specific requirement that $\mathrm{HF}, \mathrm{NH}_{4} \mathrm{HF}_{2}$ or $\mathrm{NaOH}$ must be used to remove the template makes this process complicated, time consuming and costly ${ }^{14}$. In contrast, the soft templating strategy via a supramolecular self-assembly between amphiphilic nonionic co-polymers and phenolic resins actually provides a more feasible pathway to construct $\mathrm{OMCs}^{15-17}$. The so-called solvent evaporation induced self-assembly can lead to mesoscopic micelle-resol composites-driven by the hydrogenbonding interaction (for example, $\mathrm{PhOH} \cdots \mathrm{O}$ ). The triblock co-polymer as the soft template can subsequently decompose during further thermal treatment (for example, $>400^{\circ} \mathrm{C}$ ), resulting in an ordered carbon mesostrucure ${ }^{18-20}$. Although the soft-templating method has significantly enhanced the chemistry of OMCs in the past decade, the key crosslinking reaction remains limited to the acid- or base-catalysed polycondensation of toxic phenol-formaldehyde using large amount of solvents. Moreover, relying exclusively on the chemistry of phenolic resin, which is composed of only carbon and oxygen neglects an opportunity to tune the OMC composition in situ rather than post-synthesis. Finally, the wet self-assembly method with multiple drying processes cannot be easily realized in the largescale production of membranes ${ }^{21-24}$. Thus, overcoming the drawbacks of both the hard-templating and soft-templating methods is extremely important for advancing and commercializing OMC-based technologies.

To date, the development of a facile assembly for OMC production is still highly challenging because several rigorous criteria-including strong electrostatic interactions with mesophase micelles, presence of reactive groups for polymerization and crosslinking, organized polymerization around micelle aggregates, avoidance of polymerization-induced phase separation, rigid polymer backbones to prevent mesopore collapse and ability to form carbon frameworks-must be simultaneously satisfied $^{25-30}$. In addition, the applicability of an OMC support could be tremendously enhanced if metal nanoparticles (NPs) could be in situ confined inside the pores to create a dream catalyst-restricting the growth and aggregation of metal NPs, minimizing metal loss and enabling even large reactants to undergo rapid mass transfer during heterogeneous catalysis ${ }^{31,32}$. Actually, several modifications to the soft-templating approach using metal-salt additives can result in metal NP-OMC hybrids, but the NP size is much larger than the pore size of the OMC-in other words, the NPs are not confined in the mesoporous channels ${ }^{33-35}$. The lack of suitable interactions between metal salts and phenol-formaldehyde precursors may lead to the uncontrolled growth of NPs.

In this contribution, we demonstrate a versatile mechanochemical self-assembly approach to fabricate polyphenols metal
$\left(\mathrm{Zn}^{2+}\right.$ or $\left.\mathrm{Ni}^{2+}\right)$ and poly(ethylene oxide)-poly(propylene oxide)-poly(ethylene oxide) (PEO-PPO-PEO) mesophase composites by ball milling, which offers an easy synthesis of OMCs after pyrolysis treatment. The resultant carbon materials possess a hexagonally ordered mesostructure with a narrow pore size distribution $\left(\sim 7-8 \mathrm{~nm}\right.$ ), high-surface area (up to $1,057 \mathrm{~m}^{2} \mathrm{~g}^{-1}$ ), and large pore volume (up to $0.96 \mathrm{~cm}^{3} \mathrm{~g}^{-1}$ ). In the case of the Ni-based coordination crosslinking, the reduction of ligandstabilized $\mathrm{Ni}^{2}+$ ions could occur around micelles during carbonization, therefore, inherently endowing OMCs with small $(\sim 4.35 \mathrm{~nm})$, evenly dispersed and high content $(\sim 16.1 \% \mathrm{wt}) \mathrm{Ni}$ NPs. In addition, Ni NPs confined in the mesoporous channel and carbon matrix can resist thermal treatment even at $600^{\circ} \mathrm{C}$, which is rarely achieved in carbon-supported metal catalysts. Importantly, our Ni-OMC shows an exceptional activity toward the selective hydrogenation of large biomolecules (for example, cholesteryl acetate: $\sim 1.87 \mathrm{~nm}$ ), a key process for hormone medicines that is not accessible by $\mathrm{Ni}$ supported on activated carbon. Compared with wet phenol-formaldehyde polycondensation, the essence of mechanochemical coordination polymerization relies on three features: (1) the coordination polymerization can be completed by ball milling, or in other words, the solventfree crosslinking is restricted in a specific space-void of mesophase micelles; (2) the metal-salt linkers can in situ become stable metal NPs within the pores of the OMC; (3) the solid-state polymerization can exploit monomers with no or poor solubility in solvents, a vital issue that often makes solution self-assembly fail.

\section{Results}

Fabrication of OMCs. Figure 1 describes a simple route based on the mechanochemical self-assembly of tannin, metal salts and PEO-PPO-PEO. Tannin is a renewable and inexpensive polyphenol with a molecular weight ranging from 500 to 3,500 (world production: $\sim 220,000$ ton per year), and inherent pyrogallol- and catechol-like sites on tannin that can in principle function for both hydrogen-bonding and coordination interactions (Supplementary Fig. 1). The self-assembly behaviour between tannin and an amphiphilic surfactant in solution

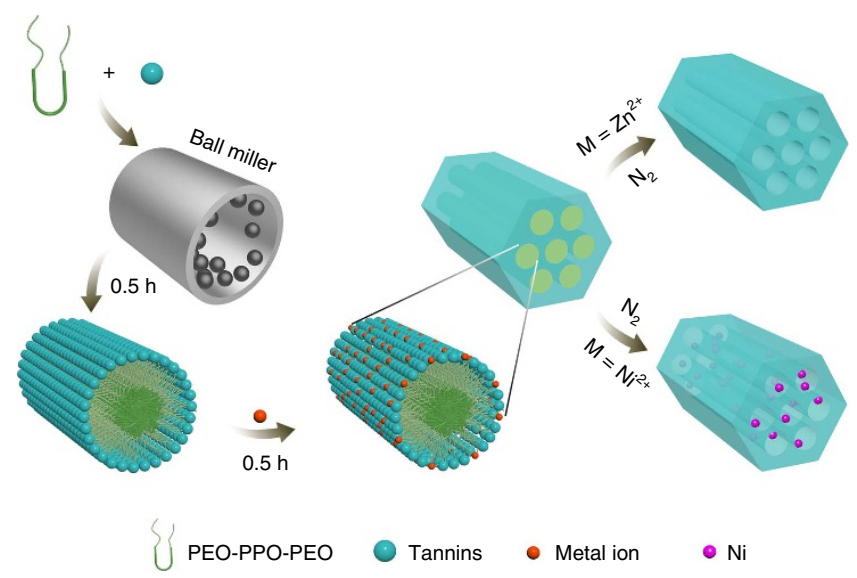

Figure 1 | Synthesis of OMCs. A proposed mechanism for the mechanochemical assembly mediated by coordination crosslinking of tannin, a biomass-derived polyphenol, with divalent metal ions in the presence of Pluronic triblock co-polymers PEO-PPO-PEO. First, the PEOPPO-PEO and tannin are ball milled for $0.5 \mathrm{~h}$, forming a brown gel. Selected metal acetates are then added to the miller, resulting in homogeneous gel nanocomposites after a short milling time $(0.5 \mathrm{~h})$. After carbonization in a $\mathrm{N}_{2}$ atmosphere, pure OMCs, or metal NP OMCs are obtained depending on the boiling point of the reduced metal species. For example, metallic $\mathrm{Zn}$ can evaporate during high-temperature treatment. 
conditions has already been confirmed by pioneering work ${ }^{36-39}$. In our current study, the ability of tannin to form hydrogenbonding networks with F127 in the solid state was explored. Tannin (1 g) and F127 (1 g) were mechanically ground in a vibrating ball miller for $30 \mathrm{~min}$. It is important to note that no solvents were used in this process. Compared with tannin, the $\mathrm{OH}$ sorption peak in the tannin-F127 mixture demonstrates a clear red shift in the Fourier transform infrared spectrum, revealing the formation of a possible hydrogen-bonding network $(\mathrm{PhOH} \cdots \mathrm{O})$ between tannin and the hydrophilic PEO blocks of F127 (Supplementary Fig. 2). The mechanochemical coordination behaviour between tannin and transition metal ions has been known with the formation of a coordination polymer product (Supplementary Fig. 3$)^{40-42}$. To crosslink tannin around F127 micelles, transition metal acetates were added into the tanninF127 mixture before ball milling for $30 \mathrm{~min}$, resulting in homogeneous gel-like composites. The tannin-F127-metal composites were finally thermally treated in a $\mathrm{N}_{2}$ atmosphere $\left(450-800^{\circ} \mathrm{C}\right)$, during which F127 micelles were completely decomposed and the tannin-metal polymer restructured into a carbon framework (Fig. 1). When $\mathrm{Zn}(\mathrm{OAc})_{2}$ was used as a linker, the tannin- $\mathrm{Zn}$ polymer with $-\mathrm{PhO}^{-}-\mathrm{Zn}^{2+}{ }_{-} \mathrm{OPh}^{-}{ }_{-}$ coordination becomes a $\mathrm{ZnO}$-carbon hybrid at a moderate temperature such as $450^{\circ} \mathrm{C}$, as observed in the diffraction lines of $\mathrm{ZnO}$ in the XRD measurement (Supplementary Fig. 4$)^{43}$. The doped $\mathrm{ZnO}$ can be reduced to metallic $\mathrm{Zn}$ during further carbonization and then evaporate resulting in pure carbon materials. The evaporation of $\mathrm{Zn}$ during calcination at $800^{\circ} \mathrm{C}$ was suggested by both inductively coupled plasma-atomic emission spectroscopy (Zn: $0.14 \mathrm{wt} \%$ ) and $\mathrm{XRD}$ results (Supplementary Fig. 5). To optimize the assembly process, a series of mesoporous carbons were prepared from tannin $(1 \mathrm{~g})$, surfactants (F127, F88, F87, F68, F38, P123, P103, P85, P65, Triton X-100 and Brij-78) and $\mathrm{Zn}(\mathrm{OAc})_{2}(3 \mathrm{mmol})$ composites under various carbonization temperatures. Those carbon materials are denoted as OMC@F127 -450 , OMC@F127 $0.8-800$ and OMC@P123 $23_{0.8}-800$ and so on, where the subscript word such as ' $\mathrm{F} 127_{0.8}$ ' corresponds $0.8 \mathrm{~g} \mathrm{~F} 127$ used, while the last number ' 800 ' indicates the pyrolysis temperature.

Both F127 and metal salts are necessary for the successful assembly of the mesoporous structure, as suggested by $\mathrm{N}_{2}$ adsorption-desorption measurements of the control products at $77 \mathrm{~K}$. The pyrolysis $\left(800^{\circ} \mathrm{C}\right)$ of tannin-F127 $(1 \mathrm{~g}: 1 \mathrm{~g})$ or tannin$\mathrm{Zn}(\mathrm{OAc})_{2}$ (1 g:3 mmol) composites derived from ball milling leads to disordered carbons with low pore volumes $\left(0.36 \mathrm{~cm}^{3} \mathrm{~g}^{-1}\right.$ and $0.23 \mathrm{~cm}^{3} \mathrm{~g}^{-1}$, respectively) (Supplementary Fig. 6 and Table 1). Similar disordered carbons with a broad pore size distribution were prepared from the carbonization of tannin acid-cobalt or -iron crystalline complexes ${ }^{44}$. In sharp contrast, carbon OMC@F127 1 -800 derived from tannin-F127-Zn(OAc) ( $1 \mathrm{~g}: 1 \mathrm{~g}: 3 \mathrm{mmol}$ ) shows an adsorption-desorption pattern of mesoporous structure (pore size: $\sim 7.8 \mathrm{~nm}$ ) with an enhanced pore volume $\left(0.69 \mathrm{~cm}^{3} \mathrm{~g}^{-1}\right)$ (Fig. 2a,b, curve $\mathrm{D}$ and Supplementary Fig. 6). This result is consistent with the proposed assembly model in which F127 micelles self-assemble to form an ordered mesophase and then $\mathrm{Zn}(\mathrm{OAc})_{2}$ crosslinks the tannin units around them.

In addition, the weight ratios of tannin to F127 (1:1, 1:0.8, 1:0.6 and 1:0.4) are flexible. The $\mathrm{N}_{2}$ adsorption-desorption measurements of carbon samples (OMC@F127 1 -800, OMC@F127 $7_{0.8}-800$, OMC@F127 $7_{0.6}-800$ and OMC@F127 $\left.7_{0.4}-800\right)$ resulted in type IV isotherms with clear $\mathrm{H} 1$ hysteresis loops, a characteristic of mesoporous materials (Fig. 2a, curves A-D). Delayed closure of the hysteresis loop for the OMC@F127 $0.4-800$ sample indicates pore constrictions along the main mesopores. Furthermore, the Brunauer-Emmett-Teller (BET)-specific surface areas calculated within the relative pressure range of $0.02-0.05$ are in the range of $621-1,057 \mathrm{~m}^{2} \mathrm{~g}^{-1}$ with single point pore volumes reaching $0.76 \mathrm{~cm}^{3} \mathrm{~g}^{-1}$ (Table 1$)^{45}$. The calculated pore size distributions ${ }^{46,47}$ are narrow and centred at $6-8 \mathrm{~nm}$, in agreement with the formation of mesopores with widths controlled by the triblock co-polymer templates of carbon materials (Fig. 2b, curves A-D). Such a mesoporous structure in fact can form at $450{ }^{\circ} \mathrm{C}$, but the OMC@F127 $1-450$ sample is in fact the mesoporous $\mathrm{ZnO}$-containing polymer (C: $68.11 \mathrm{wt} \%$, $\mathrm{H}: 3.11 \mathrm{wt} \%$ and $\mathrm{O}: 17.94 \mathrm{wt} \%)$. It is understandable since the F127 co-polymer would completely decompose at a temperature above $400{ }^{\circ} \mathrm{C}$ in an inert atmosphere ${ }^{18}$. Carbonization temperature also plays a role in controlling the mesopore size. For instance, for the OMC@F127 1 series (Supplementary Figs 7 and 8 and Table 1), the mesopore widths slightly decreased from $8.6 \mathrm{~nm}$ for OMC@F $127_{1}-450$, down to $7.8 \mathrm{~nm}$ for OMC@F127 ${ }_{1}$ 800 , indicating a slight shrinkage of the framework with increasing temperature. The amount of $\mathrm{Zn}(\mathrm{OAc})_{2}(1.8,2.4,3.0$ and $3.6 \mathrm{mmol}$ ) for coordination crosslinking can vary with all loadings resulting in the successful synthesis of mesoporous carbons (Supplementary Fig. 9). To better understand the microporous and ultramicroporous structure of the $\mathrm{OMCs}, \mathrm{CO}_{2}$ sorption measurements were performed (Fig. 2e-h and Table 1$)^{48-51}$. For two selected samples, the non local density functional theory (NLDFT)-calculated pore size distributions (PSDs) have maxima for micropore widths at $0.34-0.35 \mathrm{~nm}$, with additional pores of $\sim 0.50 \mathrm{~nm}$ confirming the presence of an important fraction of ultramicroporosity (pores narrower than $0.7 \mathrm{~nm})^{52-54}$. While the origin of these micropores is attributed to the decomposition of thermally unstable organic domains, and evolution of gaseous decomposition products within the carbon walls during carbonization, post-synthesis activation methods are necessary to further increase the micropore content of the present OMC materials ${ }^{55}$

To adjust the pore size of the carbon products, PEO-PPOPEO templates with different compositions (Pluronic F88, F87, F68, F38, P123, P103, P85, P65) and nonionic surfactants (PEO-based Triton X-100 and Brij-78) were also explored in the mechanochemical assembly with the tannin-Zn precursor. The assembly with other F-series co-polymers led to mesoporous carbons with pore sizes around $5 \mathrm{~nm}$, slightly smaller than the OMC obtained with F127 $(\sim 7 \mathrm{~nm}$ ) (Fig. 2c,d, curve F and Supplementary Fig. 10). The pore size roughly increases with the molecular weight of the PPO chain in the F-series co-polymers, which is reasonable since the size of the micelle core will increase with a longer hydrophobic PPO chain (Supplementary Table 1). The P-series co-polymers with a lower weight percentage of PEO are also interesting for the current methodology (Supplementary Fig. 11). For example, the OMC@P65 $5_{0.8}-800$ sample is composed of small mesopores of $\sim 4.2 \mathrm{~nm}$ (Fig. $2 \mathrm{c}, \mathrm{d}$, curve E), while the use of P123 in the self-assembly process can result in carbon with an extremely narrow pore size distribution around $5.4 \mathrm{~nm}$ (Fig. 2i,j). In addition to triblock co-polymers, PEO-based nonionic surfactants such as Triton $\mathrm{X}-100$ and Brij-78 were also investigated. The OMC@TritonX-100 $0.8-800$ sample is rich in mesopores of $\sim 5.0 \mathrm{~nm}$ (Supplementary Fig. 12). Interestingly, it is also possible to engineer the large mesopores through the use of Brij-78, though the pore size distribution is somewhat broadened (Supplementary Fig. 13). Previously, surfactants other than F127 and P123 had been used as soft templates with limited success and for very restricted conditions ${ }^{1,25}$. In addition, the increase of pore size (from $\sim 6.9$ to $\sim 10.4 \mathrm{~nm}$ ) could be achieved by adding $10 \mathrm{wt} \%$ hydrophobic triphenylphosphine into the F127 for a larger micelle core (Fig. 2c,d, curve G). Because of the abundant library of surfactants available, the mechanochemical selfassembly method can serve as a general method to synthesize 

Table 1 | Calculated $\mathrm{N}_{2}$ at $77 \mathrm{~K}$ adsorption parameters for the various tannin-based materials obtained with or without metal
crosslinkers, using different triblock co-polymers as templates, and under various carbonization temperatures.

\begin{tabular}{|c|c|c|c|c|c|c|}
\hline Sample & $V_{S P}\left(\mathrm{~cm}^{3} \mathrm{~g}^{-1}\right)^{\star}$ & $S_{\mathrm{BET}}\left(\mathrm{m}^{2} \mathrm{~g}^{-1}\right)^{\dagger}$ & $V_{\mathrm{mi}}\left(\mathrm{cm}^{3} \mathrm{~g}^{-1}\right)^{\ddagger}$ & $S_{m i}\left(m^{2} g^{-1}\right) \S$ & $w_{\text {KJS }}(\mathrm{nm})^{\|}$ & $V_{\mathrm{mi}} \mathrm{CO}_{2}\left(\mathrm{~cm}^{3} \mathrm{~g}^{-1}\right)$ \\
\hline C@Tannin-Zn & 0.23 & 514 & 0.20 & 469 & - & - \\
\hline C@Tannin-F127 & 0.36 & 395 & 0.11 & 245 & - & - \\
\hline OMC@F1270.4-800 & 0.59 & 773 & 0.19 & 475 & 7.3 & 0.22 \\
\hline OMC@F1270.6-800 & 0.76 & 1057 & 0.24 & 601 & 7.8 & 0.29 \\
\hline OMC@F1270.8-800 & 0.58 & 621 & 0.12 & 293 & 6.9 & 0.29 \\
\hline OMC@F127.0-450 & 0.66 & 547 & 0.08 & 180 & 8.6 & - \\
\hline OMC@F1271.0-600 & 0.67 & 869 & 0.17 & 412 & 8.2 & - \\
\hline OMC@F1271.0-800 & 0.69 & 734 & 0.16 & 390 & 7.8 & 0.18 \\
\hline Ni-OMC@F127o.8-450 & 0.96 & 996 & 0.19 & 464 & 6.9 & 0.18 \\
\hline Ni-OMC@F1270.8-600 & 0.73 & 769 & 0.15 & 356 & 7.8 & - \\
\hline Ni-OMC@F1270.8-800 & 0.52 & 558 & 0.14 & 355 & 9.2 & - \\
\hline OMC@F380.8-800 & 0.49 & 722 & 0.16 & 381 & 5.3 & - \\
\hline OMC@F680.8-800 & 0.58 & 770 & 0.15 & 350 & 5.3 & - \\
\hline OMC@F870.8-800 & 0.62 & 765 & 0.17 & 412 & 5.9 & - \\
\hline OMC@F880.8-800 & 0.61 & 733 & 0.13 & 316 & 5.7 & - \\
\hline OMC@P65o.8-800 & 0.60 & 851 & 0.15 & 340 & 4.2 & - \\
\hline OMC@P85o.8-800 & 0.66 & 770 & 0.17 & 405 & 6.6 & - \\
\hline OMC@P1030.8-800 & 0.76 & 825 & 0.19 & 466 & 7.5 & - \\
\hline OMC@P1230.8-800 & 0.73 & 811 & 0.13 & 310 & 5.4 & - \\
\hline OMC@Bj78_-800 & 0.89 & 695 & 0.16 & 382 & 17 & - \\
\hline OMC@TritonX1000.8-800 & 0.50 & 782 & 0.17 & 407 & 5.0 & - \\
\hline OMC@(F127+Ph $\left.{ }_{3} P\right)_{0.8}-800$ & 0.57 & 496 & 0.10 & 244 & 10.4 & - \\
\hline
\end{tabular}

mesoporous carbons with tunable pore sizes ranging from 4 to $10 \mathrm{~nm}$.

To further characterize the mesoporous morphology of the as-synthesized carbons, transmission electron microscopy (TEM) and scanning TEM in high angle angular dark field (STEMHAADF) images were then utilized. As expected, all F127-based carbons show ordered structures yet with different mesophases, which could be tuned by varying the ratio of F127 to the tannin precursor. The OMC@F127 $0.4-800$ and OMC@F127 $0.6-800$ samples with less F127 yield wormhole architectures and the apparent mesopores of $\sim 8 \mathrm{~nm}$ remain side by side throughout the carbon backbone (Fig. 3a-d and Supplementary Figs 14 and 15). Increasing the mass ratio of F127 in the system resulted in the OMC@F127 $7_{0.8}-800$ sample with uniform cylindrical mesopores (Fig. 3e-h). The uniformity of the mesopores extends over hundreds of nanometres, as seen in the lower-magnification STEM-HAADF image (Fig. 3e). The long-range 2D hexagonal arrays of mesoporous channels are clear in Fig. 3f,h. The higher magnification image showing the length of the pores (Fig. $3 \mathrm{~g}$ ) illustrates that the pore diameter is in a narrow range of $7.7-8.6 \mathrm{~nm}$, in good agreement with the maximum pore width calculated by $\mathrm{N}_{2}$ sorption measurements (Fig. $3 \mathrm{~g}$ ). It is interesting that the carbon wall is quite thin $(\sim 2 \mathrm{~nm})$, which is similar to large pore OMCs obtained from the solution-based softtemplating method. The small angle X-ray scattering (SAXS) data for OMC@F127 $7_{0.8}-800$ are in agreement with the periodic pore wall mesostructure (Supplementary Fig. 16). The OMC@F127 1 -800 sample with additional F127 possesses a larger mesopore volume but a less ordered structure (Supplementary Fig. 17). The P123-templated carbon shows a cubic-like mesoporous structure (Fig. $3 \mathrm{i}$ and Supplementary Fig. 18), while the porosity of the carbons with the nonionic surfactant templates primarily derives from the interstitial voids of particle aggregates (Supplementary Figs 19 and 20). The OMC@(F127- $\left.\mathrm{Ph}_{3} \mathrm{P}\right)_{0.8}-800$ sample also retains the ordered mesoporous nanoarchitecture, suggesting the possibility of introducing triphenylphosphine into the F127 micelles to enlarge the pore size (Supplementary Fig. 21). Therefore, the mechanochemical assembly of the tannin$\mathrm{Zn}$ coordination network together with F127 is a versatile solidstate self-assembly method for creating hexagonal OMCs based on renewable carbon precursors.

Fabrication of nickel OMCs. The coordination chemistry of tannin is in fact extremely rich and not limited to $\mathrm{Zn}^{2}+$ ion, which can be reduced to the corresponding metal with a low boiling point. It would be ideal if a metal NP-OMC could be directly prepared by introducing transition metals with a high boiling point into the tannin-metal coordination ${ }^{40,55}$. Consequently, $\mathrm{Ni}(\mathrm{OAc})_{2}$ was then selected for the mechanochemical polymerization process using tannin in the presence of F127. The sample was thermally treated in $\mathrm{N}_{2}$ atmosphere to generate hybrid carbon materials (Fig. 1). The carbon materials were denoted as Ni-OMC@F127 $0.8-450$, Ni-OMC@F127 $7_{0.8}-600$ and so on. The appearance of diffraction lines at $2 \theta=44.7^{\circ}, 52.0^{\circ}$ and $76.5^{\circ}$ in XRD patterns indicates the presence of metallic $\mathrm{Ni}$ in the carbons (Supplementary Fig. 22). We attribute the formation of these metallic Ni NPs to the reduction of $\mathrm{NiO}$ by neighbourhood carbons under inert atmosphere ${ }^{56}$, which can take place even at $450^{\circ} \mathrm{C}$. Based on Scherrer's equation, the average size $(5.7 \mathrm{~nm})$ of the Ni crystallites in the Ni-OMC@F127 $0.8-450$ is smaller than those in the samples synthesized with both more and less F127 (for example, NiOMC@F127 $0.6^{-450}$ and Ni-OMC@F127 -450 ) (Supplementary Fig. 22). This observation is likely due to an enhanced confining effect from the hexagonally structured carbon. The $\mathrm{N}_{2}$ adsorption-desorption measurement of Ni-OMC@F127 $7_{0.8}-450$ shows a type IV isotherm with a sharp capillary condensation 


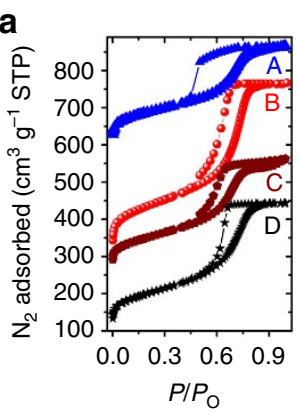

b
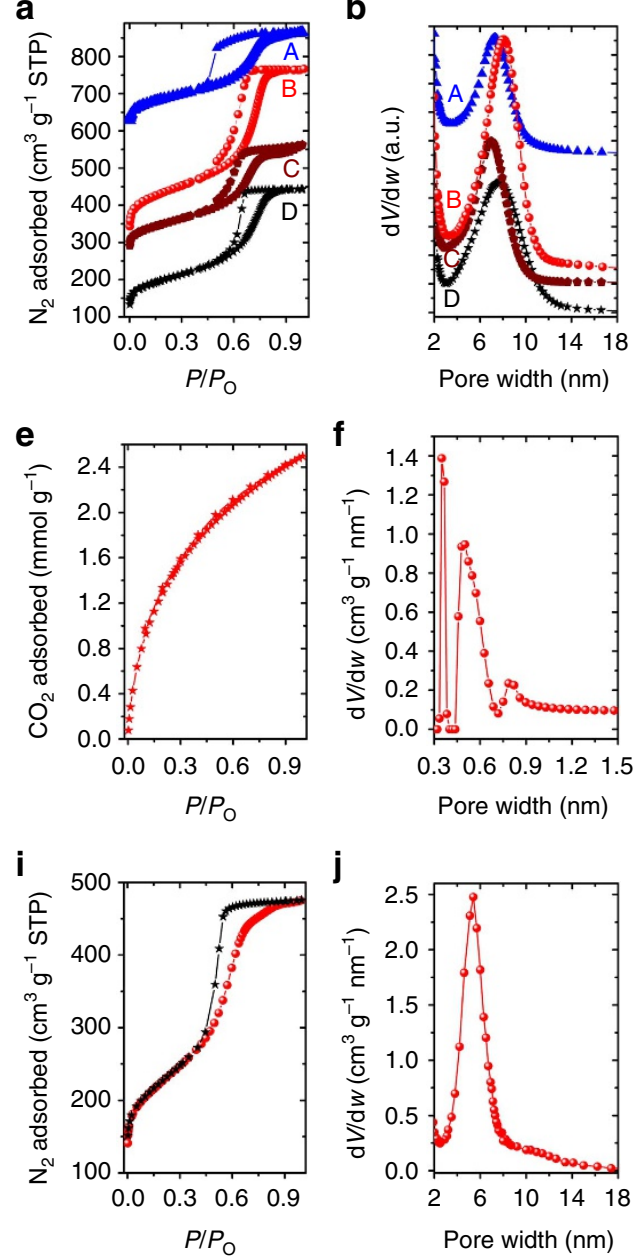
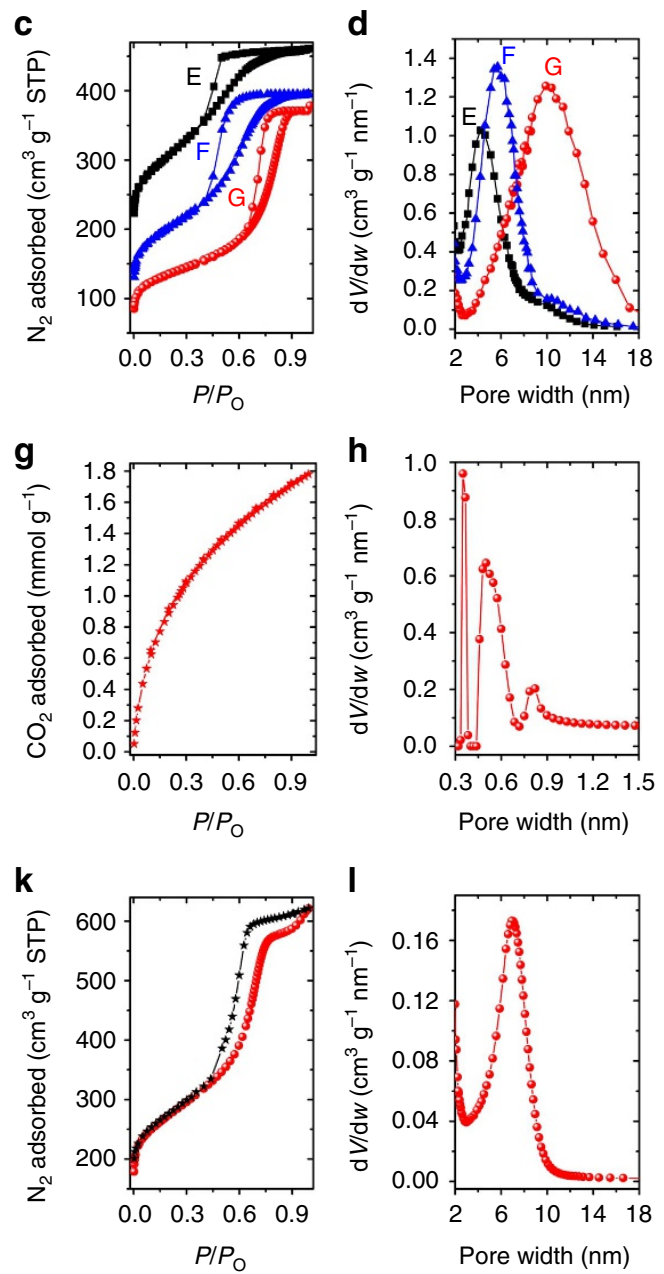

Figure 2 | Characterizations of pore structure by gas sorption. (a-d) $\mathrm{N}_{2}$ adsorption-desorption isotherms (77 K) and the corresponding pore size distributions of as-synthesized carbons. A: OMC@F1270.4-800,B: OMC@F1270.6-800, C: OMC@F1270.8-800, D: OMC@F1271-800,E: OMC@P650.8-800, F: OMC@F88 $0.8-800$ and G: OMC@(F127+Ph $\left.\mathrm{Ph}_{3} \mathrm{P}\right)_{0.8}-800$. For clarity, the isotherms of $\mathrm{A}, \mathrm{B}, \mathrm{C}$ and $\mathrm{E}$ are offset along they axis by $400 \mathrm{~cm}^{3} \mathrm{~g}-1$, $100 \mathrm{~cm}^{3} \mathrm{~g}^{-1}, 150 \mathrm{~cm}^{3} \mathrm{~g}^{-1}$ and $70 \mathrm{~cm}^{3} \mathrm{~g}^{-1}$, respectively. (e,f) $\mathrm{CO}_{2}$ adsorption-desorption isotherms $(273 \mathrm{~K}$ ) and the corresponding pore size distribution of OMC@F127 $0.6-800$ sample. (g,h) CO 2 adsorption-desorption isotherms (273 K) and the corresponding pore size distribution of OMC@P1230.8-800 sample. (i,j) $\mathrm{N}_{2}$ adsorption-desorption isotherm $\left(77 \mathrm{~K}\right.$ ) and the corresponding pore size distribution of OMC@P123 $0.8^{-800}$ sample. (k,I) $\mathrm{N}_{2}$ adsorptiondesorption isotherm (77K) and the corresponding pore size distribution of Ni-OMC@F1270.8 450 sample.

step at $P / P_{0}=\sim 0.5-0.8$ and H1-type hysteresis loop, suggesting the formation of a mesoporous structure (Fig. 2k). Meanwhile, the significant volume adsorbed at low relative pressure (for example, 0-0.1) indicates the presence of abundant micropores inside the carbon wall. The pore size distribution is quite narrow, centring at around $6.9 \mathrm{~nm}$ (Fig. 2l). A high specific surface area of $996 \mathrm{~m}^{2} \mathrm{~g}^{-1}$ with a large pore volume of $0.96 \mathrm{~cm}^{3} \mathrm{~g}^{-1}$ is observed, during which the micropores contribute around one half $\left(464 \mathrm{~m}^{2} \mathrm{~g}^{-1}\right)$ (Table 1).

As seen in the STEM-HAADF images, Ni-OMC@F127 $7_{0.8}-450$ is composed of ordered parallel channels, revealing that $\mathrm{Ni}^{2+}$ ions worked well in the mechanochemical assembly with tannin and F127. The apparent pore diameter of $\sim 7 \mathrm{~nm}$ is in excellent agreement with the calculated pore width obtained using the $\mathrm{N}_{2}$ sorption measurement (Fig. 4a,b and Supplementary Fig. 23). More importantly, Ni NPs with an average particle size of $4.4 \mathrm{~nm}$ (Fig. 4j) are well dispersed throughout the entire OMC domain. (Note that less than $1 \% \mathrm{Ni}$ NPs with a size of $\sim 14 \mathrm{~nm}$ are observed, which are likely located on the external surface of the OMC). A number of mono-dispersed Ni NPs situated at the end of the cylindrical channels are also observed from the [001] direction (Fig. 4c). High-resolution STEM-HAADF images show that Ni NPs are homogeneously embedded in either the carbon walls or the mesoporous channels (Fig. 4d,e). These Ni NPs, that is, contained within the $1 \mathrm{D}$ mesoporous cylinder channel or the carbon wall, should possess good thermal stability because of the constraint of the carbon support which limits aggregation or growth during high-temperature treatment ${ }^{57}$. To explore this confining effect, Ni-OMC samples were also prepared using higher pyrolysis temperatures $\left(600\right.$ and $800^{\circ} \mathrm{C}$ ) (Supplementary Figs 24 and 25). It is worth emphasizing that the Ni NPs within Ni-OMC@F127 $7_{0.8}-600$ still retain a highly dispersed morphology with an average size of $5.4 \mathrm{~nm}$ (Fig. $4 \mathrm{f}, \mathrm{g}, \mathrm{k}$ ). A further increase of the temperature $\left(800^{\circ} \mathrm{C}\right)$ promoted the Ni NPs growth to $\sim 10 \mathrm{~nm}$ (Fig. $4 \mathrm{~h}$ ), which may be induced by surface migration and sintering of the Ni NPs at $800^{\circ} \mathrm{C}$. Control samples with $\mathrm{Ni}$ on commercial-activated carbon (Ni-AC) or traditional softtemplated OMC (Ni-ST-OMC) were prepared by a wet impregnation method, maintaining the same $\mathrm{Ni}$ content as Ni-OMC@F127 $0.8^{-450 \quad(16.1 w t \%) . \quad S e r i o u s ~ g r o w t h ~ a n d ~}$ aggregation of the Ni NPs (up to $100 \mathrm{~nm}$ ) were observed in the $\mathrm{Ni}-\mathrm{AC}$ and Ni-ST-OMC samples (Supplementary Figs 26-29), and a similar Ni-ST-OMC sample with Ni NPs around $500 \mathrm{~nm}$ (15 $\mathrm{wt} \%)$ was also reported through carbonization of phenolic 


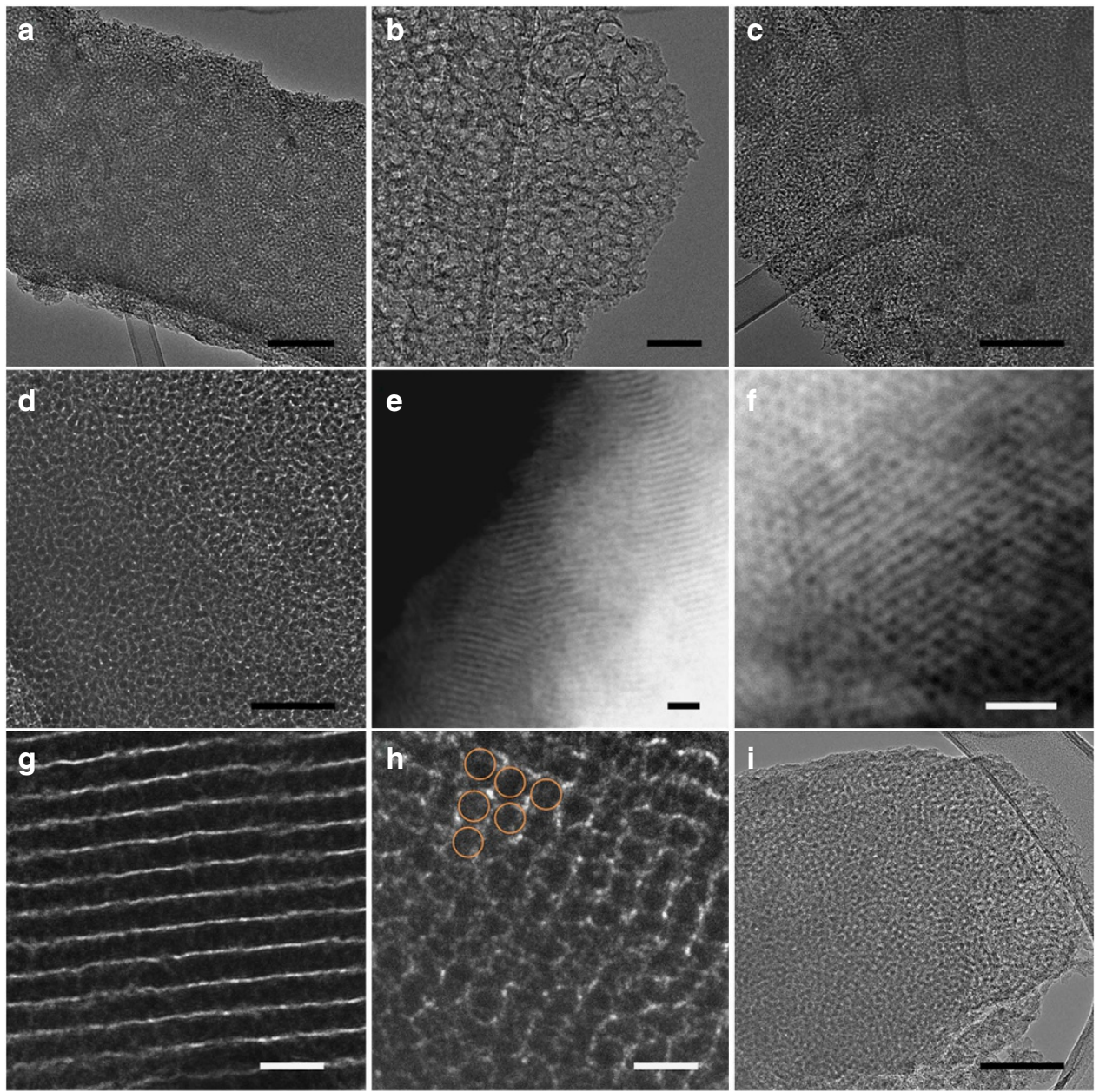

Figure 3 | Morphology and structural characterization of OMCs. (a,b) TEM images of OMC@F1270.4-800 sample. Scale bar, 200 (a) and 50 nm (b). (c,d) TEM images of OMC@F1270.6-800 sample. Scale bar, 200 (c) and 100 nm (d). (e-h) STEM-HAADF and TEM images of OMC@F1270.8-800 sample. Scale bar, $50 \mathrm{~nm}(\mathbf{e , f})$ and $20 \mathrm{~nm}(\mathbf{g}, \mathbf{h})$. (i) TEM image of OMC@P1230.8-800 sample; scale bar, $100 \mathrm{~nm}$. The orange circles in $\mathbf{h}$ show the hexagonal array of mesopores.

resin-block co-polymer-nickel nitrate composite ${ }^{58}$. Observations from these control samples indicate that the mechanochemical inorganic-organic assembly process enables NP-OMC composite materials with high NP thermal stability due to excellent confining ability of the OMC support. Current coordination assembly with abundant electron-donating ligands around the $\mathrm{Ni}^{2+}$ ions could prevent the migration of Ni NPs formed in situ in the carbon matrix, meanwhile those Ni NPs inside the 1D cylinder channels are primarily controlled by space confinement. The exceptional resistance of the Ni-OMCs to sintering during thermal treatment is of great interest in catalysis, especially considering the $\mathrm{Ni}$ loading amounts that could be achieved (16.1 wt\%).

Size-sensitive hydrogenation of alkene. The catalytic hydrogenation of alkenes to alkanes is a key process in organic synthesis ${ }^{59,60}$. Though many heterogeneous catalysts that promote this selective hydrogenation have been developed, an ideal catalyst, which is active toward large molecules, remains a significant scientific pursuit. One problem with many current catalysts originates from the slow or even difficult mass transfer of large molecules (for example, $\sim 2 \mathrm{~nm}$ ) inside narrow pores, preventing the reactant molecules from reaching the active sites smoothly ${ }^{61}$. By coupling the unique properties of OMCs (large pore size, uniform 1D pore channel and high-surface area) with the attractive features of confined Ni NPs (small particle size and high thermal stability and resistance to sintering), the Ni-OMC@F127 $7_{0.8}-450$ sample synthesized by the mechanochemical approach exhibits most of the prerequisites for an efficient catalyst for the selective hydrogenation of large molecules. To that end, the hydrogenation of cyclohexene, 1-octadecene and cholesteryl acetate, molecules with the same reactive site yet different sizes, was selected as a model reaction to evaluate Ni-OMC@F127 $0.8^{-450, N i-A C @ 450 ~ a n d ~ N i-S T-~}$ OMC@450 (Table 2). A molecular dynamics simulation in vacuum illustrates their different molecular sizes with the longest distances of 0.50, 1.97 and $1.87 \mathrm{~nm}$ (Supplementary Figs 30-32 and Supplementary Note 1). All catalysts exhibited high performance in the transformation of cyclohexene to cyclohexane, suggesting that $\mathrm{Ni}$ NPs supported on both microporous or mesoporous supports are accessible to cyclohexene $(\sim 0.5 \mathrm{~nm})$. In the case of 1-octadecene hydrogenation, Ni-OMC@F127 $7_{0.8}-450$ exhibited a high yield of 1-octadecane while Ni-AC@450 and Ni-ST-OMC@450 gave only moderate yields (65 and 77\%). In sharp contrast to the smaller molecules, the hydrogenation of the larger cholesteryl acetate showed different results. The Ni-OMC@F127 $7_{0.8}-450$ offered a good yield of $92 \%$, but limited yields were observed for the NiAC@450 and Ni-ST-OMC@450 catalysts. These results indicate that large molecules, such as 1-octadecene and cholesteryl acetate, 

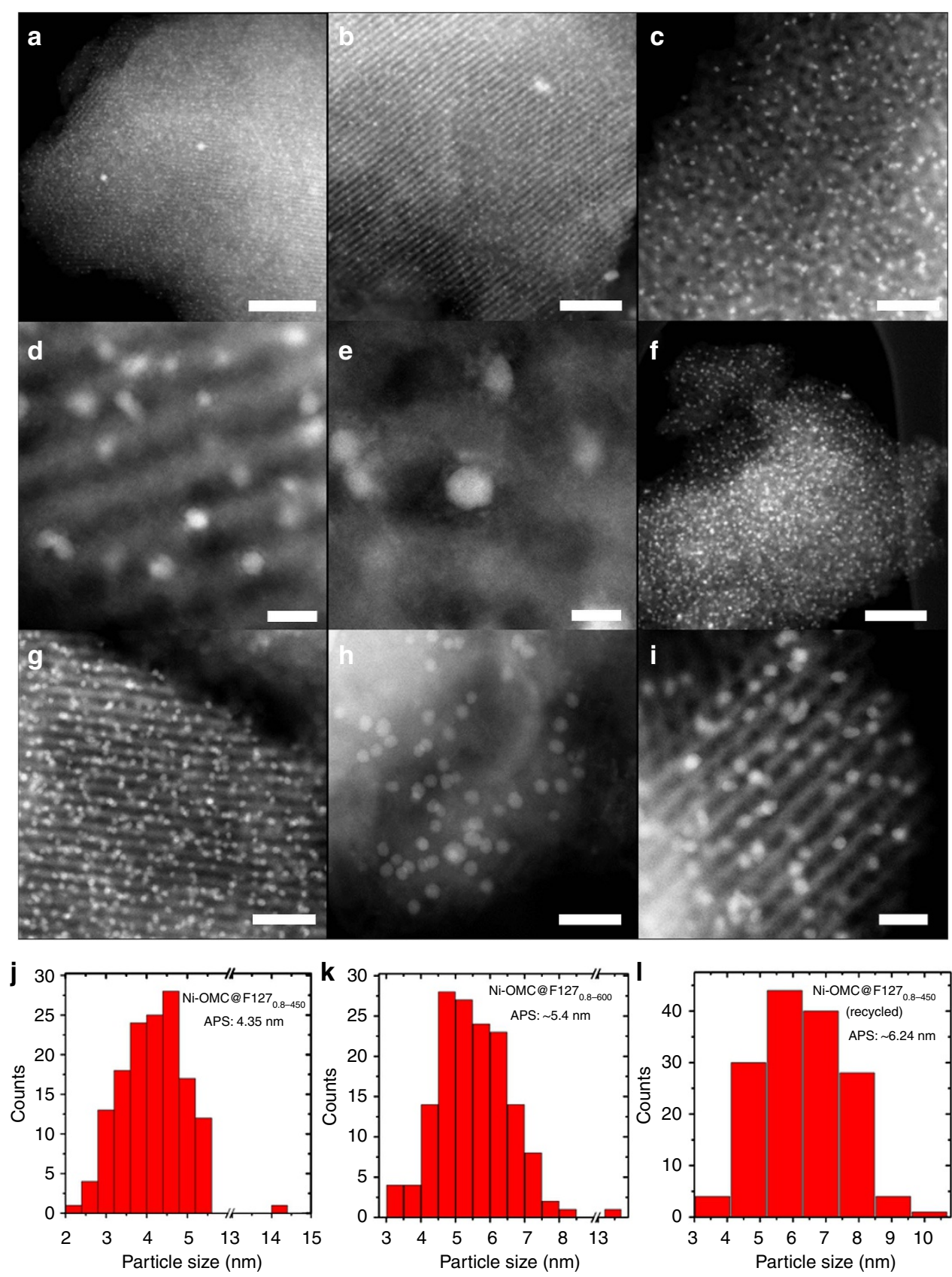

Figure 4 | Morphology and structural characterization of nickel OMCs. (a-e) STEM-HAADF images of Ni-OMC@F127 $0.8-450$. Scale bar, 200 (a), 100 (b), 50 (c), 10 (d) and $5 \mathrm{~nm}(\mathbf{e})$. (f,g) Ni-OMC@F127 $0.8-600$. Scale bar, 100 (f) and 50 nm (g). (h) Ni-OMC@F1270.8-800. Scale bar, 50 nm. (i) NiOMC@F127 $0.8^{-450}$ recycled from hydrogenation reaction; scale bar, $20 \mathrm{~nm}$. (j-I) The corresponding particle size distributions. The particle size distribution was calculated based on 150 particles randomly selected. APS, average particle size.

can be freely adsorbed on active Ni NPs of Ni-OMC@F127 $0.8^{-}$ 450. However, activated carbon or post-impregnated OMC are composed of either micropores (Supplementary Fig. 33) or mesopores that are blocked by large Ni NPs. In both cases, the bulky cholesteryl acetate with a rigid backbone was likely prevented from entering the pores and accessing the active sites. Therefore, Ni-OMC@F127 $7_{0.8}-450$ has been proven to be efficient toward the hydrogenation of various molecules (Supplementary Table 2). Moreover, the catalyst can be magnetically recycled and reused at least five times without any loss of activity (Supplementary Table 3). Further, the Ni NPs in the recycled catalyst showed only a slight increase in size from 4.35 to $6.24 \mathrm{~nm}$ after recycling (see the STEM-HAADF images in
Fig. 4i,l), once again revealing the excellent stability of $\mathrm{Ni-OMC@F127} 0.8-450$.

\section{Discussion}

In summary, a general, environmentally friendly, high throughout, mechanochemical synthesis of OMC and Ni-OMC has been realized, based on two fortuitous findings: (1) The coordination polymerization between polyphenols and metal ions can provide a versatile alternative to traditional phenol-formaldehyde polycondensation, and this process can replace the toxic organic precursors (for example, phenol, resorcinol or phloroglucinol) with biomass-derived tannin and eliminate the use of 
Table 2 | Selective hydrogenation of alkene by Ni-based catalysts. ${ }^{\star}$
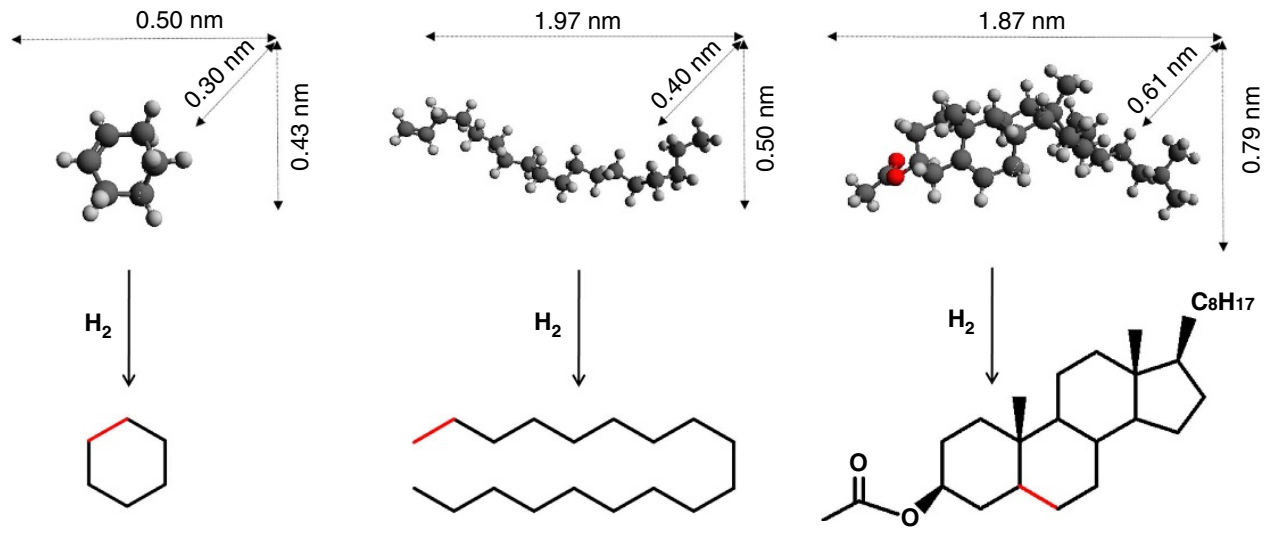

\begin{tabular}{lccc}
\hline Catalyst & Cyclohexene & 1-Octadecene & Cholesteryl acetate. \\
\cline { 2 - 4 } & Yield & Yield & Yield \\
\hline Blank & $8 \%$ & $<1 \%$ & $<1 \%$ \\
Ni-OMC@F127 0.8 -450 & $98 \%$ & $96 \%$ & $92 \%$ \\
Ni-AC@450 & $97 \%$ & $65 \%$ & $10 \%$ \\
Ni-ST-OMC@450 & $98 \%$ & $77 \%$ & $24 \%$
\end{tabular}

${ }^{\star}$ Reaction conditions: cyclohexene or 1 -octadecene $1 \mathrm{mmol}$, decane (internal standard: $1 \mathrm{mmol}$ ), ethanol $3 \mathrm{ml}$, Ni catalyst $10 \mathrm{mg}, \mathrm{H}_{2} 3 \mathrm{MPa}, 130{ }^{\circ} \mathrm{C}, 2 \mathrm{~h}$; or cholesteryl acetate $0.5 \mathrm{mmol}$, acetone $10 \mathrm{ml}, \mathrm{Ni}$ catalyst $10 \mathrm{mg}, \mathrm{H}_{2} 3 \mathrm{MPa}, 130^{\circ} \mathrm{C}, 2 \mathrm{~h}$.

carcinogenic crosslinkers, that is, formaldehyde. Other transition metal ions with vacant orbital that readily coordinate to catechol are potential metal species for the current assembly. Various metal NPs/oxides/carbides could in principle be in situ confined inside the OMCs, adding another dimension to enrich the current OMC library. (2) The mechanochemical synthesis that runs under solid conditions can guarantee the crosslinking polymerization undergoing within the voids of the F127 mesophases, shortening the assembly time to $1 \mathrm{~h}$, much less than the processing time (1-3 days) of the solution route ${ }^{62}$. The solidstate assembly also avoids solvent wastes (for example, water, ethanol or tetrahydrofuran), and favourably allows the use of precursors with no or low solubility in solvents.

OMCs with hexagonal cylindrical structures have been prepared with large pore size $(\sim 8 \mathrm{~nm})$, narrow pore size distribution and high pore volume (up to $0.96 \mathrm{~cm}^{3} \mathrm{~g}^{-1}$ ). Importantly, the coordination polymer allows in situ reduction of $\mathrm{Ni}^{2}+$ ions into $\mathrm{Ni} \mathrm{NPs}$, which are also confined and highly dispersed in the OMCs. Those Ni-OMCs show excellent thermal stability up to $600^{\circ} \mathrm{C}$ ( Ni NPs: $\sim 5.4 \mathrm{~nm}$ ). Ni-OMCs were also successfully used for the selective hydrogenation of large molecules $(\sim 2 \mathrm{~nm})$ with high yield, once again highlighting the unique features of the mesoporous catalysts. Meanwhile, the introduction of mechanochemical synthesis by ball milling together with the inexpensive, abundant and biomass-derived tannin precursor $(<\$ 20$ per $\mathrm{kg})$ make the OMC-based technologies promising for practical applications (Supplementary Table 4). In addition to tannin, tannin derivatives, such as ellagotannins, gallotannins, quercetin and ellagic acid, and low-weight molecule lignin are also potential resources for OMC production.

\section{Methods}

General methods and characterization. $\mathrm{N}_{2}$ adsorption-desorption analysis was performed at $77 \mathrm{~K}$ using a TriStar (Micromeritics Instrument Corp.; Norcross, GA, USA), equipped with automated surface area and pore size analyser. Before analysis, samples were degassed at $200^{\circ} \mathrm{C}$ for $24 \mathrm{~h} . \mathrm{CO}_{2}$ adsorption isotherms were acquired at $273 \mathrm{~K}$ using a Quantachrome Autosorb-1. Before analysis, samples were allowed to outgas at $200^{\circ} \mathrm{C}$ under turbomolecular vacuum pumping for a minimum of $15 \mathrm{~h}$. For TEM and STEM characterization, samples were dispersed in ethanol using an ultrasonic bath. The final suspensions were transferred to TEM grids and dried in ambient air before electron microscopy analysis. The material morphology was visualized using STEM-HAADF images and electron energy loss spectroscopy on a Nion UltraSTEM 200 microscope operated at $200 \mathrm{kV}$. Powder $\mathrm{X}$-ray diffraction (XRD) and SAXS were measured on a Bruker D8 diffractometer equipped with scintillation counter. The $\mathrm{Zn}$ and $\mathrm{Ni}$ contents were measured by inductively coupled plasma-atomic emission spectroscopy. All gas chromatography experiments were carried out and recorded by Agilent Technology 7890A. Fourier transform infrared spectrum was collected by PerkinElmer Frontier Fourier transform infrared spectrometer. Mimosa tannin from SILVACHIMICA S.r.l. (Italy) was used as the carbon precursor.

Synthesis of OMC and Ni-OMC by ball milling. In a typical synthesis, tannin $(1 \mathrm{~g})$ and F127 (0.4-1 g) were added to a commercially available $4.5 \mathrm{~cm}$ (diameter) by $5.5 \mathrm{~cm}$ (height) screw-capped stainless steel reactor along with six stainless steel ball bearings $(2 \times$ diameter $1.2 \mathrm{~cm} ; 2 \times$ diameter $0.7 \mathrm{~cm} ; 2 \times$ diameter $0.5 \mathrm{~cm}$. total weight: $230 \mathrm{~g})$. The reactor was placed in a high-speed vibrating ball miller $(1,200$ rounds $\min ^{-1}, 300 \mathrm{~W}$ motor power) and the mixtures were ball milled for $30 \mathrm{~min}$. Then, $\mathrm{Zn}(\mathrm{OAc})_{2} \cdot \mathrm{H}_{2} \mathrm{O}$ or $\mathrm{Ni}(\mathrm{OAc})_{2} \cdot \mathrm{H}_{2} \mathrm{O}(3 \mathrm{mmol})$ was added into the reactor for ball milling in another $30 \mathrm{~min}$. The resulting gel-like products were washed with deionized $\mathrm{H}_{2} \mathrm{O}$ and ethanol, followed by drying at room temperature overnight. The composites were finally carbonized at $450^{\circ} \mathrm{C}$ (heating rate: $5 \mathrm{~K} \mathrm{~min}^{-1}$, holding time: $2 \mathrm{~h})$, or at $600 / 800^{\circ} \mathrm{C}\left(5 \mathrm{Kmin}^{-1}\right.$ to $450^{\circ} \mathrm{C}$ for $2 \mathrm{~h}$ and then $5 \mathrm{Kmin}^{-1}$ to final temperature for a holding time of $2 \mathrm{~h}$ ) under an inert $\mathrm{N}_{2}$ atmosphere $\left(\mathrm{N}_{2} 200 \mathrm{ml} \mathrm{min}^{-1}\right)$. The synthesis with other surfactants follows the same process.

Selective hydrogenation of different sized molecules. The selective hydrogenation was carried out in a stainless steel batch reactor (Parr Instrument, USA). Typically, cyclohexene or 1-octadecene $(1 \mathrm{mmol})$, decane (internal standard, $1 \mathrm{mmol})$, ethanol $(3 \mathrm{ml})$ and $\mathrm{Ni}$ catalyst $(10 \mathrm{mg})$ were loaded into the reactor (total volume: $100 \mathrm{ml}$ ). The reactor was sealed and purged with $\mathrm{H}_{2}$ to replace the air for four times. The $\mathrm{H}_{2}$ pressure was kept at $3 \mathrm{MPa}$, and the reactor was heated to $130^{\circ} \mathrm{C}$ for $10 \mathrm{~min}$. Then, the hydrogenation reaction was carried out for $2 \mathrm{~h}$ with magnetic stirring (stirring rate: 800 r.p.m.). After reaction, the reactor was placed in cold water to quench the reaction. The oxidation products were analysed by gas chromatography. Due to the solubility issue, hydrogenation of cholesteryl acetate was carried out in acetone solvent. Cholesteryl acetate $(0.5 \mathrm{mmol}, 0.214 \mathrm{~g})$, acetone $(10 \mathrm{ml})$ and $\mathrm{Ni}$ catalyst $(10 \mathrm{mg})$ were loaded into the reactor (total volume: $100 \mathrm{ml}$ ), followed by a same process as above. After completion of the reaction, the solvent was removed under reduced pressure at $45^{\circ} \mathrm{C}$. The residue was purified by silica gel column chromatography (ethyl acetate/petroleum ether $=1 / 11$ ) to afford $3 \beta$ acetoxy-5 $\alpha$-cholestane as white powder. The product was analysed by ${ }^{1} \mathrm{H}-\mathrm{NMR}$ spectroscopy in $\mathrm{CDCl}_{3}$ and elemental analysis. ${ }^{1} \mathrm{H}-\mathrm{NMR}\left(500 \mathrm{MHz}, \mathrm{CDCl}_{3}\right)$ : 
$\delta=0.64\left(\mathrm{~s}, 3 \mathrm{H}, 18-\mathrm{CH}_{3}\right), 0.85\left(\mathrm{~d}, J=6.6 \mathrm{~Hz}, 6 \mathrm{H}, 26-\mathrm{CH}_{3}, 27-\mathrm{CH}_{3}\right), 0.90$ (d, $\left.J=6.5 \mathrm{~Hz}, 3 \mathrm{H}, 21-\mathrm{CH}_{3}\right), 1.20\left(\mathrm{~s}, 3 \mathrm{H}, 19-\mathrm{CH}_{3}\right), 2.03$ (s, 3H, 29- $\left.\mathrm{CH}_{3} \mathrm{CO}\right), 4.64$ (m, 1H, 3-CH).

Data availability. All relevant data are available from the authors on reasonable request.

\section{References}

1. Wan, Y., Shi, Y. F. \& Zhao, D. Y. Supramolecular aggregates as templates: ordered mesoporous polymers and carbons. Chem. Mater. 20, 932-945 (2008).

2. Kong, B. et al. Incorporation of well-dispersed sub-5-nm graphitic pencil nanodots into ordered mesoporous frameworks. Nat. Chem. 8, 171-178 (2016).

3. Tüysüz, H. \& Schüth, F. Ordered mesoporous materials as catalysts. Adv. Catal. 55, 127-239 (2012).

4. Lin, T. et al. Nitrogen-doped mesoporous carbon of extraordinary capacitance for electrochemical energy storage. Science 350, 1508-1513 (2015).

5. Ji, X. et al. Nanocrystalline intermetallics on mesoporous carbon for direct formic acid fuel cell anodes. Nat. Chem. 2, 286-293 (2010).

6. Wang, X. et al. Sulfonated ordered mesoporous carbon as a stable and highly active protonic acid catalyst. Chem. Mater. 19, 2395-2397 (2007).

7. Zhang, J., Zhao, Z., Xia, Z. \& Dai, L. M. A metal-free bifunctional electrocatalyst for oxygen reduction and oxygen evolution reactions. Nat. Nanotechnol. 10, 444-452 (2015).

8. Huang, P. et al. On-chip and freestanding elastic carbon films for microsupercapacitors. Science 351, 691-695 (2016).

9. Lee, J., Kim, J. \& Hyeon, T. Recent progress in the synthesis of porous carbon materials. Adv. Mater. 18, 2073-2094 (2006).

10. Johnson, S. A., Ollivier, P. J. \& Mallouk, T. E. Ordered mesoporous polymers of tunable pore size from colloidal silica templates. Science 283, 963-965 (1999).

11. Lu, A. H. \& Schüth, F. Nanocasting: a versatile strategy for creating nanostructured porous materials. Adv. Mater. 18, 1793-1805 (2006).

12. Ryoo, R., Joo, S. H. \& Jun, S. Synthesis of highly ordered carbon molecular sieves via template-mediated structural transformation. J. Phys. Chem. B 103, 7743-7746 (1999).

13. Lee, J., Yoon, S., Hyeon, T., Oh, S. M. \& Kim, K. B. Synthesis of a new mesoporous carbon and its application to electrochemical double-layer capacitors. Chem. Commun. 1999, 2177-2178 (1999).

14. Choi, K. M. \& Kuroda, K. Double function of tris(hydroxymethyl)aminomethane (THAM) for the preparation of colloidal silica nanospheres and the conversion to ordered mesoporous carbon. Chem. Commun. 47, 10933-10935 (2011).

15. Zhang, F. Q. et al. A facile aqueous route to synthesize highly ordered mesoporous polymers and carbon frameworks with $\mathrm{Ia} 3^{-} d$ bicontinuous cubic structure. J. Am. Chem. Soc. 127, 13508-13509 (2005).

16. Warren, S. C. et al. Ordered mesoporous materials from metal nanoparticleblock copolymer self-assembly. Science 320, 1748-1752 (2008).

17. Lukens, W. W. \& Stucky, G. D. Synthesis of mesoporous carbon foams templated by organic colloids. Chem. Mater. 14, 1665-1670 (2002).

18. Meng, Y. et al. Ordered mesoporous polymers and homologous carbon frameworks: amphiphilic surfactant templating and direct transformation. Angew. Chem. Int. Ed. 44, 7053-7059 (2005).

19. Tanaka, S., Nishiyama, N., Egashira, Y. \& Ueyama, K. Synthesis of ordered mesoporous carbons with channel structure from an organic-organic nanocomposite. Chem. Commun. 2005, 2125-2127 (2005).

20. Liang, C. D. \& Dai, S. Synthesis of mesoporous carbon materials via enhanced hydrogen-bonding interaction. J. Am. Chem. Soc. 128, 5316-5317 (2006).

21. Ma, T. Y., Liu, L. \& Yuan, Z. Y. Direct synthesis of ordered mesoporous carbons. Chem. Soc. Rev. 42, 3977-4003 (2013).

22. Morris, R. E. Some difficult challenges for the synthesis of nanoporous materials. Top. Catal. 53, 1291-1296 (2010).

23. Zhang, H. W. et al. Surfactant-Free assembly of mesoporous carbon hollow spheres with large tunable pore sizes. ACS Nano 10, 4579-4586 (2016).

24. Titirici, M. M., Thomas, A. \& Antonietti, M. Aminated hydrophilic ordered mesoporous carbons. J. Mater. Chem. 17, 3412-3418 (2007).

25. Wan, Y., Yang, H. F. \& Zhao, D. Y. 'Host - guest' chemistry in the synthesis of ordered nonsiliceous mesoporous materials. Acc. Chem. Res. 39, 423-432 (2006).

26. Schuster, J. et al. In situ SAXS study on a new mechanism for mesostructure formation of ordered mesoporous carbons: thermally induced self assembly. J. Am. Chem. Soc. 134, 11136-11145 (2012).

27. Poyraz, A. S., Kuo, C. H., Biswas, S., King’ondu, C. K. \& Suib, S. L. A general approach to crystalline and monomodal pore size mesoporous materials. Nat. Commun. 4, 2952 (2013).

28. Liu, J. et al. A facile soft-template synthesis of mesoporous polymeric and carbonaceous nanospheres. Nat. Commun. 4, 2789 (2013).

29. Liu, J., Wickramaratne, N. P., Qiao, S. Z. \& Jaroniec, M. Molecular-based design and emerging applications of nanoporous carbon spheres. Nat. Mater. 14, 763-774 (2015).
30. Petkovich, N. D. \& Stein, A. Controlling macro- and mesostructures with hierarchical porosity through combined hard and soft templating. Chem. Soc. Rev. 42, 3721-3739 (2013).

31. Larisha, C., Pedro, S. \& Corma, A. Selective reductive coupling of nitro compounds with aldehydes to nitrones in $\mathrm{H}_{2}$ using carbon-supported and decorated platinum nanoparticles. Angew. Chem. Int. Ed. 53, 9306-9310 (2014).

32. Pan, X. L. et al. Enhanced ethanol production inside carbon-nanotube reactors containing catalytic particles. Nat. Mater. 6, 507-511 (2007).

33. Gorka, J. \& Jaroniec, M. Incorporation of Inorganic nanoparticles into mesoporous carbons synthesized by soft templating. J. Phy. Chem. C 112, 11657-11660 (2008).

34. Kang, E. et al. $\mathrm{Fe}_{3} \mathrm{O}_{4}$ nanoparticles confined in mesocellular carbon foam for high performance anode materials for lithium-ion batteries. Adv. Funct. Mater. 21, 2430-2438 (2011).

35. Fuertes, A. B., Sevilla, M., Valdes-Solis, T. \& Tartaj, P. Synthetic route to nanocomposites made up of inorganic nanoparticles confined within a hollow mesoporous carbon shell. Chem. Mater. 19, 5418-5423 (2007).

36. Schlienger, S., Graff, A. L., Celzard, A. \& Parmentier, J. Direct synthesis of ordered mesoporous polymer and carbon materials by a biosourced precursor. Green Chem. 14, 313-316 (2012).

37. Braghiroli, F. L., Fierro, V., Parmentier, J., Pasc, A. \& Celzard, A. Easy and eco-friendly synthesis of ordered mesoporous carbons by selfassembly of tannin with a block copolymer. Green Chem. 18, 3265-3271 (2016).

38. Szczurek, A., Fierro, V., Pizzi, A. \& Celzard, A. Emulsion-templated porous carbon monoliths derived from tannins. Carbon 74, 352-362 (2014).

39. Braghiroli, F. L. et al. Nitrogen-doped carbon materials produced from hydrothermally treated tannin. Carbon 50, 5411-5420 (2012).

40. McDonald, M., Mila, I. \& Scalbert, A. Precipitation of metal ions by plant polyphenols: optimal conditions and origin of precipitation. J. Agric. Food Chem. 44, 599-606 (1996).

41. Zhang, P. F., Li, H. Y., Veith, G. M. \& Dai, S. Soluble porous coordination polymers by mechanochemistry: from metal-containing films/membranes to active catalysts for aerobic oxidation. Adv. Mater. 27, 234-239 (2015).

42. Morris, R. E. Coordination chemistry in the solid state. Dalton Trans. 41, 3867-3868 (2012).

43. Yang, S. J., Antonietti, M. \& Fechler, N. Self-assembly of metal phenolic mesocrystals and morphosynthetic transformation toward hierarchically porous carbons. J. Am. Chem. Soc. 137, 8269-8273 (2015).

44. Wei, J. et al. Hydrothermal synthesis of metal-polyphenol coordination crystals and their derived metal/n-doped carbon composites for oxygen electrocatalysis. Angew. Chem. Int. Ed. 55, 12470-12474 (2016).

45. Rouquerol, J., Llewellyn, P. \& Rouquerol, F. Is the BET equation applicable to microporous adsorbents? Stud. Surf. Sci. Catal. 160, 49-53 (2007).

46. Choma, J., Gorka, J. \& Jaroniec, M. Mesoporous carbons synthesized by soft-templating method: determination of pore size distribution from argon and nitrogen adsorption isotherms. Micropor. Mesopor. Mater. 112, 573-579 (2008).

47. Kruk, M., Jaroniec, M. \& Sayari, A. Application of large pore MCM-41 molecular sieves to improve pore size analysis using nitrogen adsorption measurements. Langmuir 13, 6267-6273 (1997).

48. Vishnyakov, A., Ravikovitch, P. I. \& Neimark, A. V. Molecular level models for $\mathrm{CO}_{2}$ sorption in nanopores. Langmuir 15, 8736-8742 (1999).

49. Jagiello, J. \& Thommes, M. Comparison of DFT characterization methods based on $\mathrm{N}_{2}, \mathrm{Ar}, \mathrm{CO}_{2}$, and $\mathrm{H}_{2}$ adsorption applied to carbons with various pore size distributions. Carbon 42, 1227-1232 (2004).

50. Lozano-Castelló, D., Cazorla-Amorós, D. \& Linares-Solano, A. Usefulness of $\mathrm{CO}_{2}$ adsorption at $273 \mathrm{~K}$ for the characterization of porous carbons. Carbon $\mathbf{4 2}$ 1233-1242 (2004).

51. Ravikovitch, P. I., Vishnyakov, A., Russo, R. \& Neimark, A. V. Unified approach to pore size characterization of microporous carbonaceous materials from $\mathrm{N}_{2}, \mathrm{Ar}$ and $\mathrm{CO}_{2}$ adsorption isotherms. Langmuir 16, 2311-2320 (2000).

52. Kruk, M., Li, Z., Jaroniec, M. \& Betz, W. R. Nitrogen adsorption study of surface properties of graphitized carbon blacks. Langmuir 15, 1435-1441 (1999).

53. Jaroniec, M., Kruk, M. \& Olivier, J. P. Standard nitrogen adsorption data for characterization of nanoporous silicas. Langmuir 15, 5410-5413 (1999).

54. Kruk, M., Jaroniec, M. \& Choma, J. Comparative analysis of simple and advanced sorption methods for assessment of microporosity in activated carbons. Carbon 36, 1447-1458 (1998).

55. Fierro, V., Muniz, G., Basta, A. H., EI-Saied, H. \& Celzard, A. Rice straw as precursor of activated carbons: activation with ortho-phosphoric acid. J. Hazard. Mater. 181, 27-34 (2010).

56. Anton, R. On the reaction kinetics of $\mathrm{Ni}$ with amorphous carbon. Carbon 46, 656-662 (2008). 
57. Sun, Z. et al. A general chelate-assisted Co-assembly to metallic nanoparticlesincorporated ordered mesoporous carbon catalysts for Fischer - Tropsch synthesis. J. Am. Chem. Soc. 134, 17653-17660 (2012).

58. Wang, X. \& Dai, S. A simple method to ordered mesoporous carbons containing nickel nanoparticles. Adsorption 15, 138-144 (2009).

59. Zhang, P. F. et al. Improving hydrothermal carbonization by poly(ionic liquid)s. Angew. Chem. Int. Ed. 52, 6028-6032 (2013).

60. Enache, D. I., Hutchings, G. J., Taylor, S. H. \& Stitt, E. H. The hydrogenation of isophorone to trimethyl cyclohexanone using the downflow single capillary reactor. Catal. Today 105, 569-573 (2005).

61. Kärgera, J. \& Valiullin, R. Mass transfer in mesoporous materials: the benefit of microscopic diffusion measurement. Chem. Soc. Rev. 42, 4172-4197 (2013).

62. Friščić, T. et al. Real-time and in situ monitoring of mechanochemical milling reactions. Nat. Chem. 5, 66-73 (2013).

\section{Acknowledgements}

P.F.Z., S.M.M., Y.Z. and S.D. were supported by the Division of Chemical Sciences, Geosciences, and Biosciences, Office of Basic Energy Sciences, U.S. Department of Energy. L.W. and X.F.L. were supported by the National Basic Research Program of China (2013CB933201) and the National High Technology Research and Development Program of China (2015AA034603). The electron microscopy at ORNL (S.Z.Y. and M.F.C.) was supported by the U.S. Department of Energy, Office of Science, Basic Energy Sciences, Materials Sciences and Engineering Division.

\section{Author contributions}

P.F.Z. and S.D. conceived and designed the experiments. P.F.Z. and L.W. performed all the experiments and analysed all the data. S.Z.Y. and M.F.C. obtained STEM-HAADF

images and X.F.L. worked for the TEM images. S.M.M. performed the SAXS measurement. Y.Z. completed the molecular dynamics simulation. J.A.S. carried out the $\mathrm{CO}_{2}$ sorption measurement. P.F.F. and J.A.S. calculated the gas adsorption parameters. All authors discussed the results and commented on the manuscript. P.F.Z. wrote the paper and P.F.F. and S.D. revised the paper.

\section{Additional information}

Supplementary Information accompanies this paper at http://www.nature.com/ naturecommunications

Competing interests: The authors declare no competing financial interests.

Reprints and permission information is available online at http://npg.nature.com/ reprintsandpermissions/

How to cite this article: Zhang, P. et al. Solid-state synthesis of ordered mesoporous carbon catalysts via a mechanochemical assembly through coordination cross-linking. Nat. Commun. 8, 15020 doi: 10.1038/ncomms15020 (2017).

Publisher's note: Springer Nature remains neutral with regard to jurisdictional claims in published maps and institutional affiliations.

\section{(c) (i)} article are included in the article's Creative Commons license, unless indicated otherwise in the credit line; if the material is not included under the Creative Commons license, users will need to obtain permission from the license holder to reproduce the material. To view a copy of this license, visit http://creativecommons.org/licenses/by/4.0/
(C) The Author(s) 2017 